Published in final edited form as:

Biomaterials. 2015 June ; 54: 1-8. doi:10.1016/j.biomaterials.2015.02.118.

\title{
Food-associated Stimuli Enhance Barrier Properties of Gastrointestinal Mucus
}

\author{
Hasan M. Yildiz ${ }^{\mathrm{a}}$, Lauren Speciner ${ }^{\mathrm{b}}$, Cafer Ozdemir ${ }^{\mathrm{c}}$, David E. Cohen ${ }^{\mathrm{c}}$, and Rebecca L. \\ Carriera, ${ }^{*}$ \\ a Department of Chemical Engineering, Northeastern University, 360 Huntington Avenue, Boston, \\ MA, 02115, USA \\ b Department of Bioengineering, Northeastern University, 360 Huntington Avenue, Boston, MA, \\ 02115, USA \\ c Department of Medicine, Division of Gastroenterology, Brigham and Women's Hospital, Harvard \\ Medical School 77 Avenue Louis Pasteur, Boston, Massachusetts 02115, USA
}

\begin{abstract}
Orally delivered drugs and nutrients must diffuse through mucus to enter the circulatory system, but the barrier properties of mucus and their modulation by physiological factors are generally poorly characterized. The main objective of this study was to examine the impact of physicochemical changes occurring upon food ingestion on gastrointestinal (GI) mucus barrier properties. Lipids representative of postprandial intestinal contents enhanced mucus barriers, as indicated by a $10-142$-fold reduction in the transport rate of $200 \mathrm{~nm}$ microspheres through mucus, depending on surface chemistry. Physiologically relevant increases in $\left[\mathrm{Ca}^{2+}\right]$ resulted in a 2 - 4-fold reduction of transport rates, likely due to enhanced cross-linking of the mucus gel network. Reduction of $\mathrm{pH}$ from 6.5 to 3.5 also affected mucus viscoelasticity, reducing particle transport rates approximately 5 - 10-fold. Macroscopic visual observation and micro-scale lectin staining revealed mucus gel structural changes, including clumping into regions into which particles did not penetrate. Histological examination indicated food ingestion can prevent microsphere contact with and endocytosis by intestinal epithelium. Taken together, these results demonstrate that GI mucus barriers are significantly altered by stimuli associated with eating and potentially dosing of lipid-based delivery systems; these stimuli represent broadly relevant variables to consider upon designing oral therapies.
\end{abstract}

\section{Keywords}

oral drug delivery; mucus; mucosal barriers; food effect; diffusion

\footnotetext{
(C) 2015 Published by Elsevier Ltd.

* Correspondence: Rebecca L. Carrier, Advanced Drug Delivery Research Lab, 342 Snell Engineering Center, Northeastern University, Boston, MA 02115, Phone: 617-373-7126, Fax: 617-373-2209, r.carrier@ neu.edu.

Publisher's Disclaimer: This is a PDF file of an unedited manuscript that has been accepted for publication. As a service to our customers we are providing this early version of the manuscript. The manuscript will undergo copyediting, typesetting, and review of the resulting proof before it is published in its final citable form. Please note that during the production process errors may be discovered which could affect the content, and all legal disclaimers that apply to the journal pertain.
} 


\section{INTRODUCTION}

Mucus consists of a highly branched protein network, the major structural component of which is mucin glycoproteins [1]. Mucus also contains approximately $2 \%$ lipids and $90-95 \%$ salts, cells, electrolytes, other cellular debris, and water [2,3]. Intestinal mucus functions as a robust barrier to control the passage of harmful molecules and organisms such as bacteria, but allows efficient transport of nutrients across the epithelium. These conflicting functions are significant to establishing effective drug and nutrient transport across intestinal mucosa [4].

Ingested lipids are known to impact intestinal absorption. Most nutrients are lipid soluble; vitamins and cholesterol are solubilized in mixed micelles, which are formed from foodassociated levels of bile salts and phospholipids [5]. The influence of lipids on orally delivered drug compound absorption across intestinal mucosa originates in part from colloidal structures the lipids form.[6] Lipids are also endogenously present in mucus, and include cholesterol, ceramide, palmitic acid, stearic acid, oleic acid, linoleic acid, and other free fatty acids [7, 8]. It has been demonstrated that removal of lipids from airway mucus significantly alters viscoelastic properties $[9,10]$. Extraction of lipids from gastric mucus led to $80-85 \%$ decrease in viscosity [11]. Lipid content and composition are also known to affect the viscoelasticity in expectorated airway secretions from cystic fibrosis patients [12, 13]. Furthermore, enhancement of mucociliary transport capacity has been correlated with the recovery of phospholipid content in airway mucus [14]. However, in spite of the tremendous physiological relevance of exposure of intestinal mucus to lipid mixtures originating from food or drug delivery systems, the potential impact of exogenous lipids on barrier properties of intestinal mucus has not been explored. Mineral salts are also associated with food intake, and comprise a mass percentage up to $1 \%$ in mucus [2]. Mucus properties depend in part on ionic interactions between mucins, and salts can thus directly alter mucus structure [15-17]. Monomers of the main secreted intestinal mucin, MUC2, form intermolecular links with $\left[\mathrm{Ca}^{2+}\right]$ that increase mucus viscoelasticiy $[17,18]$. After food arrival, $\left[\mathrm{Ca}^{2+}\right]$ concentration varies in the small intestine. Reported calcium ion concentration prior to eating is between 4 to $5 \mathrm{mM}$, and it could reach up to $20 \mathrm{mM}$ after eating [19]. While multiple reports have demonstrated the impact of $\left[\mathrm{Ca}^{2+}\right]$ on physical properties of mucin solutions $[16,17]$, the impact of exogenous $\left[\mathrm{Ca}^{2+}\right]$ on transport through native intestinal mucus has not been characterized.

Gastrointestinal $\mathrm{pH}$ also plays an important role in modulating drug delivery and nutrient absorption [20]. After food arrival, median small intestinal $\mathrm{pH}$ is approximately 5.4, whereas median fasting $\mathrm{pH}$ is close to 6.1. However, $\mathrm{pH}$ values fluctuate between individuals from a minimum as low as $\mathrm{pH} 3.1$ to a maximum of $\mathrm{pH} 6.7$ [21]. Acidity is known to alter gastric mucin solution rheological and structural properties [22]. Decreasing $\mathrm{pH}$ has been demonstrated to induce gastric mucin aggregation and increase gastric mucin solution viscosity $[23,24]$. It has been suggested that this is due to neutralization of glycosidic residues, however analysis of native and deglycosylated gastric mucin aggregation at low $\mathrm{pH}$ using atomic force microscopy indicated that oligosaccharide side chains are not required for mucin aggregation to occur [25]. It is unclear if similar $\mathrm{pH}$ effects are also 
observed in intestinal mucus, especially as the main gel-forming mucin in intestine (MUC2) is different from that in stomach (MUC5AC).

In this investigation, the impact of exposure to lipids and physicochemical stimuli, including $\mathrm{pH}$ and $\left[\mathrm{Ca}^{2+}\right]$ variations, associated with eating on particle transport through intestinal mucus has been investigated using microstructural analysis and real-time multiple particle tracking (MPT). MPT is a powerful technique that enables probing of particle-environment interactions by tracking the motion of hundreds of individual microspheres [26, 27].

Diffusive particle transport is relevant as it probes the barrier properties of mucus microenvironment, in particular to micro-scale entities such as drug delivery systems or microbes. Particle solutions containing lipids, varied $\mathrm{pH}$ levels, and varied $\left[\mathrm{Ca}^{2+}\right]$ were directly exposed to native mucus collected from porcine small intestine, or intact excised small intestine tissue from mouse. Impact of exposure to stimuli in vivo was tested by oral dosing of lipids to rat.

In summary, while it has been indicated that endogenous lipids impact mucus viscoelastic properties, and $\left[\mathrm{Ca}^{2+}\right]$ and $\mathrm{pH}$ changes are significant to mucin solution viscoelastic properties, the majority of relevant studies have been conducted on mucins isolated from non-intestinal (e.g., airways, stomach) anatomical sites. This is particularly important given the variations in mucins expressed at different anatomical locations [28]. The impact of exogenous lipids and other physicochemical intestinal lumen changes associated with food intake on transport properties of intestinal mucus have not been characterized. Here, we utilize MPT and structural analysis to demonstrate that food-associated physicochemical stimuli significantly alter barrier properties of intestinal mucus, with important implications pertaining to physiological control of exposure to ingested microparticles and microbes, and oral drug delivery.

\section{MATERIALS AND METHODS}

\subsection{Preparation and Characterization of Microspheres and Test Media}

Fluorescently labeled yellow-green FluoSpheres (Invitrogen Molecular Probes, Carlsbad, CA) were used to prepare particle suspensions. Amine-, carboxylate-, and sulfate-modified microspheres ( $200 \mathrm{~nm}$ diameter, $2 \%$ solids in distilled water with $2 \mathrm{mM}$ azide) were diluted in various test media (Table 1)[29] for a final particle concentration of $0.0025 \mathrm{wt} .-\%$. The different particle surface functionalities were utilized to test the impact of varied chemistries on interaction with mucus components during transport through mucus. Fed intestinal state was mimicked with maleate buffer ( $\mathrm{pH} 6.5,10 \mathrm{mM} \mathrm{CaCl}_{2}$ ), $12 \mathrm{mM}$ bile salt (sodium taurodeoxycholate, NaTDC), $4 \mathrm{mM}$ phospholipids (lecithin), and a lipid mixture comprised of $35 \mathrm{mM}$ soybean oil, $30 \mathrm{mM}$ sodium oleate, and $15 \mathrm{mM}$ monoglycerol. Solution was mixed on a stirring plate at $37^{\circ} \mathrm{C}$ with a continuous magnetic stirring at $300 \mathrm{rpm}$. Physiologically relevant $\mathrm{pH}$ values of 5.5 and 6.5 were obtained by adjusting $\mathrm{NaOH}$ concentration in maleate buffer $\left(10 \mathrm{mM}\right.$ in $\left.\mathrm{CaCl}_{2}\right)$ to $30 \mathrm{mM}$ and $40 \mathrm{mM}$. A low $\mathrm{pH}$ of 3.5 , indicating extreme conditions in the upper intestine where stomach contents are released, was obtained by not adding $\mathrm{NaOH}$ into maleate buffer. $\left[\mathrm{Ca}^{2+}\right]$ concentrations of 5,10 , and $20 \mathrm{mM}$ at $\mathrm{pH} 6.5$ were achieved by changing $\mathrm{CaCl}_{2}$ concentration in maleate buffer. The 
particle sizes and zeta potentials ( $\zeta$-potentials) of the polystyrene microspheres were determined using dynamic light scattering (SI text).

\subsection{Native Mucus Collection and Preparation}

Porcine intestines (Research 87, Boylston, MA) were obtained from a local abattoir within 2 hours of slaughter. Native mucus was scraped with a spatula from pig jejunum and stored at $-80^{\circ} \mathrm{C}$ until use, as previously described [30].

\subsection{Ex vivo Preparation of Excised Mouse Intestine}

Intestinal tissue segments approximately $1 \mathrm{~cm}$ in length were taken approximately $10 \mathrm{~cm}$ from the exit of the stomach, corresponding to the jejunum, from 3 week old FVB/N type mice. Mice were euthanized via $\mathrm{CO}_{2}$. Intestine fragments were cut open to expose the intestinal lumen, and placed into a chamber on a microscope slide maintained in a humidified environment.

\subsection{In vivo Dosing of Lipid}

Male rats (Sprague-Dawley), 70-90 days old, 300-375 g in weight, were dosed $2 \mathrm{ml}$ of control (water) or test lipid system (soybean oil) by oral gavage. Prior to dosing, the soybean oil was stained with $0.01 \%$ Sudan IV solution, allowing for observation of soybean oil solution in the gastrointestinal tract using fluorescence microscopy after oral dosing. Rats were anesthetized using 2.5-3\% isoflurane vapor according to IACAUC approved protocols. The abdominal cavity was entered by way of a $2 \mathrm{~cm}$ midline abdominal skin incision positioned $1 \mathrm{~cm}$ below the diaphragm along the linea alba. Using a 22 gauge needle, $50 \mu \mathrm{l}$ carboxylate-modified microspheres $200 \mathrm{~nm}$ in diameter diluted in PBS $(0.0025 \mathrm{wt} .-\%)$ were injected into the duodenal lumen. Rats were kept anesthetized under $2.5 \%$ isoflurane on a warm blanket for $30 \mathrm{~min}$ to allow microspheres to disperse throughout the lumen. Intestinal (jejunum) tissue segments approximately $1 \mathrm{~cm}$ in length were excised approximately $10 \mathrm{~cm}$ from the exit of the stomach. Microspheres were imaged using fluoresence microscopy of intact tissue for tracking experiments. Approximately $1 \mathrm{~cm}$ segments of duodenum were collected for histology.

\subsection{MPT of Microspheres in Intestinal Mucus}

The trajectories of fluorescently labeled microspheres were captured and recorded with a frame rate of $30 \mathrm{fps}$ for $20 \mathrm{~s}$ using a 12.5 megapixel cooled Olympus DP70 digital color camera (Olympus, Center Valley, PA) mounted on an inverted Olympus IX51 microscope attached with X-Cite 120 fluorescence system (EXFO, Mississauga, Ontario, Canada). Excised tissue obtained after in vivo exposure to stimuli or for ex vivo exposure was placed within chambers formed by $0.8 \mathrm{~mm}$ deep silicone gaskets (Grace Bio-Labs) attached to microscope slides. Scraped mucus was placed within non-fluorescent 8-well polystyrene medium chambers (Thermo Fisher Scientific, Rochester, NY). Diluted particle suspension $(10 \mu \mathrm{l}, 0.0025 \% \mathrm{wt} / \mathrm{vol})$ was deposited with minimal perturbation onto approximately $200 \mu \mathrm{l}$ of scraped native mucus or $10 \mathrm{~mm}$ excised mouse explant tissue segments. The mucosal specimens were covered and equilibrated for $2 \mathrm{~h}$ at $25^{\circ} \mathrm{C}$ in a humid chamber prior to microscopy. Trajectories of at least 100 microspheres were analyzed for each experiment 
and three experiments were performed from three different mucus specimens for each experimental setup to account for mucus variability. Trajectories for each particle type were generated using the feature point detection and tracking algorithm of the ParticleTracker ImageJ plugin developed by Sbalzarini et al [31]. Particle coordinates were transformed into time-averaged MSD as MSD $=[\mathrm{x}(\mathrm{t}+\tau)-\mathrm{x}(\mathrm{t})]^{2}+[\mathrm{y}(\mathrm{t}+\tau)-\mathrm{y}(\mathrm{t})]^{2}$ and effective diffusivities $\left(D_{\text {eff }}\right)$ as $\mathrm{D}_{\text {eff }}=\mathrm{MSD} /(4 \tau)$ where $\mathrm{x}(\mathrm{t})$ and $\mathrm{y}(\mathrm{t})$ represent the microsphere coordinates at a given time, and $\tau$ is the time scale. The extent of particle interaction with the mucus gel network was determined by fitting particle MSD vs. time scale to MSD $=4 \mathrm{D}_{0} \tau^{\mathrm{a}}$, where $\mathrm{a}$ is the anomalous exponent indicating particle motion obstruction and $\mathrm{D}_{0}$ is time independent diffusion coefficient [27]. Data represent the ensemble average of three separate experiments. A one tailed, unequal variance Student's $t$-test was used to evaluate significance $(\mathrm{P}<0.05)$. Particle diffusion coefficients were also used to estimate the fraction of microspheres expected to penetrate intestinal mucus layers of given thickness using a numerical integration of Fick's second law: $\delta \mathrm{C} / \mathrm{dt}=\mathrm{D}_{\text {eff }} \delta^{2} \mathrm{C} / \delta \mathrm{x}^{2}$ where $\mathrm{C}$ is the concentration of particles, $\mathrm{t}$ is time and $\mathrm{x}$ is position [32].

\subsection{Analysis of Mucus Structure}

Scraped porcine mucus ( $80 \mu \mathrm{l}$ ) was stained with $4 \mu \mathrm{l}$ of $10 \mu \mathrm{g} / \mathrm{ml}$ lectin from Ulex europaeus agglutinin (UEA-1) conjugated with TRITC (Sigma Aldrich- L4889). After 20 min incubation in a dark humid chamber, $4 \mu \mathrm{l}$ of yellow-green fluorescently labeled carboxylatemodified microspheres (diameter: $0.2 \mu \mathrm{m}$ ) diluted in test medium was added as a model particulate system and allowed to diffuse into the mucus for $2 \mathrm{~h}$ in a dark humid chamber. Structure visualized via lectin staining and relative positions of mucus and microspheres were assessed using a Zeiss LSM 700 confocal microscope. Macro-scale changes in mucus structure were visually observed and imaged for each type of preparation.

\subsection{Histology}

Rat small intestine specimens obtained after in vivo oral dosing were fixed in Carnoy's solution (60\% ethanol, $30 \%$ chloroform and $10 \%$ glacial acetic acid) for 2 hours at $4{ }^{\circ} \mathrm{C}[33$, 34]. Specimens were embedded in paraffin, and $5 \mu \mathrm{m}$ thick sections were stained using UEA-1 lectin conjugated with TRITC $(25 \mu \mathrm{g} / \mathrm{ml})$ to detect mucins and Hoescht $33342(10$ $\mu \mathrm{g} / \mathrm{ml}$ ) to image nuclei using a Zeiss LSM 700 confocal microscope.

\section{RESULTS}

\subsection{Impact of lipids on particle transport}

Intestinal contents characteristic of the fed state, including model bile and partially digested triglyceride, markedly hindered particle transport through collected porcine intestinal mucus (Figure 1). Coordinates of fluorescently labeled polystyrene microspheres with differing surface chemistry were captured using real-time MPT and transformed into time-averaged mean squared displacements (MSDs) at various time scales (Figure 1A-C), which were used to calculate effective diffusivities and viscous/elastic moduli, and to estimate particle penetration percentages across physiologically relevant thicknesses of mucus (supporting information (SI) text). The ensemble-average particle transport rates decreased with time, as expected in a heterogeneous medium such as mucus. At a time scale of $1 \mathrm{~s}$, amine-, 
carboxylate-, and sulfate modified microspheres dosed to mucus in lipid contents mimicking the fed state were 3-, 30- and 2-fold slower, respectively, than microspheres dosed to mucus in maleate buffer (Figure 1A-C). Average a values, parameters modeling MSD dependence on time scale reflective of diffusive $(a=1)$ or sub-diffusive $(a<1)$ motion, were reduced from 0.46 to $0.018,0.74$ to 0.09 , and 0.87 to 0.36 for amine-, carboxylate-, and sulfatemodified microspheres, respectively, dosed in fed state compared to maleate buffer, highlighting the high degree of transport hindrance by the presence of lipids.

In an attempt to uncouple the effects of lipid digestion products from effects of bile components in fed state medium, transport of microspheres in maleate buffer containing model bile components (NaTDC and phosphatidylcholine) only was also studied. In the fasted state, bile salt and phospholipid (BS/PL) concentrations are approximately $5 \mathrm{mM}$ and $1.25 \mathrm{mM}$, respectively, rising to $12 \mathrm{mM}$ and $4 \mathrm{mM}$ upon eating, when food-associated lipids (mainly triglycerides) are introduced. Transport analyses indicate that both food-associated triglycerides and elevated bile levels play an important role in modulating the properties of the gastrointestinal mucus barrier. Microspheres dosed to mucus in model bile were less mobile compared to those dosed in maleate buffer solution. At a time scale of $10 \mathrm{~s}$, the ensemble-average $\mathrm{D}_{\text {eff }}$ of amine-, carboxylate- and sulfate-modified microspheres were reduced 2.5, 4, and 5.5-fold, respectively, in the presence of BS/PL (Figure S1A-C). However, comparison to fed state reveals significant impact of lipids in addition to BS/PL. Ensemble averaged effective diffusivities of microspheres at $\tau=10 \mathrm{~s}$ were hindered 4, 35, and 2-fold, respectively, in fed state medium relative to maleate buffer with BS/PL.

To probe structural changes in the porcine mucus gel network upon addition of lipids, the time scale-dependent displacements were used to quantify the frequency-dependent viscous or loss modulus, $G^{\prime \prime}$, and elastic or storage modulus $G^{\prime}$ (SI Text). For all microspheres studied, gastrointestinal mucus poses higher elastic modulus than viscous modulus, indicating a gel-like network structure. Furthermore, the increase in elastic modulus with addition of lipids is greater than that of viscous modulus, indicating strengthening of the mucus gel (Figure S2).

There were moderate changes in particle size when particles were diluted in the various test media, as measured by dynamic light scattering (Figure S3). However, experimentally measured changes in diffusivity when microspheres are dosed to mucus in different media are larger than changes expected due to particle size (SI Table 1). Diffusion coefficients were predicted to be reduced 1.1-, 1.27-, and 1.28-fold for amine-, carboxylate-, and sulfatemodified microspheres dosed in fed state medium relative to maleate buffer, compared to 10-, 142-, and 10-fold experimentally measured reductions upon dosing to mucus. These results indicate that the experimentally measured changes in diffusivities are not only due to changes in particle size.

Particle mobilities when dosed to mucus in maleate buffer were inversely related to surface potential (Figure S3). Cationic amine-modified microspheres $(9.19 \pm 1.98 \mathrm{mV})$ had the lowest ensemble-average $D_{\text {eff }}\left(0.00575 \mu \mathrm{m}^{2} / \mathrm{s}\right)$, while anionic carboxylate-modified microspheres had an intermediate zeta potential $(-13.3 \pm 1.5 \mathrm{mV})$ and $\mathrm{D}_{\text {eff }}\left(0.04342 \mu \mathrm{m}^{2} / \mathrm{s}\right)$, and sulfate-modified microspheres had the most negative zeta potential $(-21.2 \pm 2.1 \mathrm{mV})$ 
and ensemble averaged $D_{\text {eff }}\left(0.06205 \mu \mathrm{m}^{2} / \mathrm{s}\right)$ at a time scale of $1 \mathrm{~s}$. Fed state intestinal contents slightly decreased measured surface potential of carboxylate- $(-14.8 \pm 2.5 \mathrm{mV})$ and sulfate-modified microspheres $(-24.4 \pm 1.6 \mathrm{mV})$, while decreasing ensemble averaged $\mathrm{D}_{\text {eff }}$ to $\left(0.00133 \mu \mathrm{m}^{2} / \mathrm{s}\right)$ and $\left(0.02184 \mu \mathrm{m}^{2} / \mathrm{s}\right)$, respectively, at a time scale of $1 \mathrm{~s}$, indicating surface potential was not responsible for observed changes in particle transport in fed state medium exposed to mucus.

To determine if lipids would have a similar effect on mucus that was intact on intestinal tissue, the mucosal surface of a mouse intestinal explant collected immediately after sacrifice was exposed to microspheres diluted in fed state medium or maleate buffer. Intestinal contents characteristic of the fed state reduced transport rates (as reflected in $<\mathrm{MSD}>$ ) of microspheres over 5-fold compared to buffer at a time scale of $10 \mathrm{~s}$ (Figure 2A). To further test if similar effects would be seen with oral dosing of oil in vivo, microspheres were injected into the duodenum of rats 1 hour after orally dosing soybean oil or water (control). Oral dosing of soybean oil reduced microsphere transport rate 10-fold at a time scale of $10 \mathrm{~s}$ (Figure 2B).

Ultimately, the significance of changes in mucus barrier properties depends on the ability of various entities, including drug carrier systems, microbes, etc., to reach the underlying epithelium. The thickness of the mucus lining the gastrointestinal tract varies from 10 to 200 m. $[35,36]$ Percent penetration of a dosed particle population across a mucus barrier of a given thickness can be estimated using a mathematical model based on Fick's second law and effective diffusivities of microspheres (Figure S4). In the absence of lipids, carboxylate- and sulfate-modified microspheres are predicted to partially penetrate mucus layers up to $\sim 100 \mathrm{~m}$ thick in about an hour, a time frame on the same order as the mucus turnover rate, reported to be 50-270 $\mathrm{min}$ [37], whereas amine-modified microspheres are predicted to not penetrate mucus layers greater than $\sim 40 \mathrm{~m}$ thick. Upon addition of foodassociated lipids, estimated predicted particle penetration significantly decreases, as carboxylate- and amine-modified microspheres cannot penetrate mucus layers greater than $\sim 20 \mathrm{~m}$, and sulfate-modified microspheres partially penetrate through a $50 \mathrm{~m}$ mucus layer (Figure S4A).

To assess translation of ex vivo results to actual oral dosing of lipids, rats were orally dosed soybean oil or water (control) 1 hour before dosing microspheres directly to the duodenum. Duodenum segments were collected 1 hour after dosing microspheres, fixed, and processed for histology. The microspheres dosed post-soybean oil ingestion were not able to reach the epithelial surface, while those dosed post-water ingestion reached the epithelial surface, as evidenced by visualization of numerous microspheres within the epithelium (Figure 3).

\subsection{Influence of $\left[\mathrm{Ca}^{2+}\right]$ and $\mathrm{pH}$ on particle transport}

Exposure of intestinal mucus to physiologically relevant increases in $\left[\mathrm{Ca}^{2+}\right]$ and decreases in $\mathrm{pH}$ provided additional evidence that food-associated stimuli enhance mucus barrier properties. With increasing $\left[\mathrm{Ca}^{2+}\right]$, the mobility of all types of microspheres in intestinal mucus decreased (Figure 1D-F). 
At a time scale of $10 \mathrm{~s}$, the ensemble-average effective diffusivity $\mathrm{D}_{\text {eff }}$ of amine-, carboxylate-, and sulfate-modified microspheres dosed at $\left[\mathrm{Ca}^{2+}\right]$ of $20 \mathrm{mM}$ were 3-, 4-, and 2-fold lower, respectively, than those of the same microspheres dosed at $\left[\mathrm{Ca}^{2+}\right]$ of $5 \mathrm{mM}$ (Figure S1D-F). The decrease in diffusivity with an increase in $\left[\mathrm{Ca}^{2+}\right]$ translated to a decrease in estimated particle penetration (Figure S4B). At a mucus layer thickness of 50 $\mu \mathrm{m}$, predicted carboxylate- and sulfate- modified particle penetration decreases from approximately $31 \%$ to $18 \%$ and $45 \%$ to $37 \%$, respectively, with an increase in $\left[\mathrm{Ca}^{2+}\right]$ from $10 \mathrm{mM}$ to $20 \mathrm{mM}$. It was again predicted that very few amine-modified microspheres would penetrate a $50 \mu \mathrm{m}$ thick mucus layer within $1 \mathrm{~h}$ of dosing at both $\left[\mathrm{Ca}^{2+}\right]=10 \mathrm{mM}$ and 20 $\mathrm{mM}$.

Given the similarity in reported mucus mesh and particle sizes, it is likely that enhanced mucin cross-linking and associated mucus structural changes are responsible in large part for observed impact of $\left[\mathrm{Ca}^{2+}\right]$ on transport. However, impact of medium $\left[\mathrm{Ca}^{2+}\right]$ on particle surface potential and size may also contribute. With an increase in $\left[\mathrm{Ca}^{2+}\right]$ from $5 \mathrm{mM}$ to 20 $\mathrm{mM}$, zeta potential of cationic amine-modified microspheres increased from $7.74 \pm 1.65 \mathrm{mV}$ to $14.56 \pm 2.19$ and anionic carboxylate- and sulfate-modified particle zeta potential values increased from $-16.2 \pm 1.12 \mathrm{mV}$ to $-5.13 \pm 0.96 \mathrm{mV}$ and $-24.6 \pm 1.5 \mathrm{mV}$ to $-8.45 \pm 2.05$ $\mathrm{mV}$, respectively (Figure S3B). Thus, electrostatic interactions between mucus proteins and microspheres were potentially responsible for decreases in amine-modified particle effective diffusivities from $0.0053 \mu \mathrm{m}^{2} / \mathrm{s}$ to $0.0021 \mu \mathrm{m}^{2} / \mathrm{s}$ and carboxylate- and sulfate-modified particle effective diffusivities from $0.065 \mu \mathrm{m}^{2} / \mathrm{s}$ to $0.018 \mu \mathrm{m}^{2} / \mathrm{s}$ and $0.079 \mu \mathrm{m}^{2} / \mathrm{s}$ to 0.041 $\mu^{2} / \mathrm{s}$, respectively (Figure S1D-F). Furthermore, effective diameters of all microspheres increased upon addition of $\left[\mathrm{Ca}^{2+}\right]$ from $5 \mathrm{mM}$ to $20 \mathrm{mM}$ (Figure S5B). However, changes in diffusivity of microspheres in maleate buffer from $\left[\mathrm{Ca}^{2+}\right]=5 \mathrm{mM}$ to $20 \mathrm{mM}$ expected based on particle size change indicated that other factors likely contribute to observed changes in diffusivities. Effective diffusivity decreases of 1.07-, 1.12-, and 1.14-fold for amine-, carboxylate-, and sulfate-modified microspheres dosed in buffer at $\left[\mathrm{Ca}^{2+}\right]=20 \mathrm{mM}$ relative buffer at $\left[\mathrm{Ca}^{2+}\right]=5 \mathrm{Mm}$ are expected based on Stokes-Einstein equation calculations (Table S1), compared to 3-, 4-, and 2-fold experimental reductions.

As the $\mathrm{pH}$ of the dosing solution decreases, particle mobility becomes more hindered (Figure 1G-I). At a time scale of $10 \mathrm{~s}$, amine-, carboxylate-, and sulfate-modified particle ensemble averaged effective diffusivities were reduced 5.5-, 10.2-, and 10.8- fold, respectively, with a decrease of $\mathrm{pH}$ from 6.5 to 3.5 (Figure S1G-I). Estimations of particle penetration again indicate that acidic conditions strongly impact the significance of a physiologically relevant mucus barrier thickness to particle translocation (Figure S4C). At pH 6.5, carboxylate-, and sulfate-modified microspheres would be able to partially penetrate a $100 \mu \mathrm{m}$ mucus layer, whereas at $\mathrm{pH} 3.5$ all microspheres are essentially not able to penetrate mucus layer over $50 \mu \mathrm{m}$ thick.

Zeta potential measurements were moderately dependent upon the $\mathrm{pH}$ of the medium (Figure 3C). Highly acidic environment ( $\mathrm{pH} 3.5$ ) significantly alters particle surface charge relative to $\mathrm{pH} 5.5$ and 6.5, which could influence particle diffusivities. At $\mathrm{pH} 3.5$, cationic amine-modified microspheres have the highest zeta potential $(16.65 \pm 2.02 \mathrm{mV})$ and lowest ensemble-average $D_{\text {eff }}\left(0.0013 \mu \mathrm{m}^{2} / \mathrm{s}\right)$ (Figure S1G). Similarly, anionic carboxylate- and 
sulfate-modified microspheres have surface charge closer to neutral $(-2.12 \pm 0.8 \mathrm{mV}$ and $-6.15 \pm 1.6 \mathrm{mV})$ and the lowest effective diffusivities $\left(0.0044 \mu \mathrm{m}^{2} / \mathrm{s}\right.$ and $\left.0.0067 \mu \mathrm{m}^{2} / \mathrm{s}\right)$

(Figure S1H-I), as expected due to electrostatic interactions between negatively charged mucus glycoproteins and microspheres.

\subsection{Mucus structural changes upon exposure to stimuli}

Food-associated stimuli differentially affected mucus structure and associated particle location within gastrointestinal mucus. Microspheres dosed in maleate buffer alone $\left(\left[\mathrm{Ca}^{2+}\right]\right.$ $=10 \mathrm{mM})\left(\right.$ Figure 4A) and maleate buffer at elevated calcium concentration, $\left[\mathrm{Ca}^{2+}\right]=20$ $\mathrm{mM}$ (Figure 4B) were fairly uniformly distributed throughout mucus. Microspheres were generally located in regions of minimal or no lectin staining, separated by regions on the order of $10 \mu \mathrm{m}$ or less which stained positively with the lectin Ulex europaeus agglutinin I (UEA1). Microspheres dosed in the fed state medium (Figure 4D) as well as in highly acidic ( $\mathrm{pH}$ 3.5) medium (Figure 4C) were generally not uniformly distributed across mucus structure, but rather accumulated at outer edges of regions on the order of $100 \mu \mathrm{m}$ in size and diffusely staining with lectin.

Changes in mucus structure upon exposure to food-associated stimuli were also macroscopically visible (Figure 5). Exposure to media containing higher $\left[\mathrm{Ca}^{2+}\right]$ appeared to result in moderate clumping of mucus, creating a less homogenous medium (Figure $\mathbf{5 F}, \mathbf{H}$ ) relative to untreated mucus (Figure 5B) or mucus exposed to buffer not containing $\mathrm{Ca}^{2+}$ (Figure 5D). Microspheres dosed in maleate buffer at pH 3.5 (Figure 5J) and in fed state medium (Figure 5L) induced a dramatic clumping of mucus into dense regions with clear boundaries from surrounding fluid. The observed clumping phenomenon correlated with hindered particle transport in mucus.

\section{DISCUSSION}

Mucus barrier properties play a significant role in modulating drug delivery and microbe proximity to epithelial surfaces. Using model particulates, the impact of exogenous lipids and other physicochemical stimuli associated with food intake on transport properties of intestinal mucus were revealed in this study utilizing MPT and structural image analysis. Lipids, which can originate from food or drug delivery vehicles, can have tremendous impact on absorption and bioavailability of orally delivered compounds, yet these effects are poorly understood and not currently amenable to prediction $[6,38,39]$. Overall, mucus barrier mechanisms for particulate as well as small molecule transport to epithelial surfaces, and for protection of epithelial cells against pathogen invasion, are not completely characterized. In particular, the potential role that food-associated stimuli, such as lipids, may play in modulating the intestinal mucus barrier has not been explored. In this study, it has been demonstrated that food-associated lipids and physicochemical changes can significantly impede particle transport through mucus.

Our results suggest that intestinal mucus elasticity increases upon the addition of exogenous lipids associated with food and certain lipid-based drug delivery systems (Figure S2). Early studies indicated that mucins secreted by tracheal epithelial cells are closely associated with lipids [40, 41]. It has been suggested that endogenous mucin-associated lipids are important 
contributors to mucus barrier properties for hydrophobic drugs, as lipophilic drug diffusion was hindered in preparations of lipids associated with mucins [42]. It is likely that the exogenous lipids present in the GI tract and studied here also interact with hydrophobic mucin and/or mucus components. While hydrophobic entities in mucus likely interact with lipids to alter mucus gel properties, the precise mechanism is not clear.

One contributing factor to altered particle transport is changes in size resulting from adsorption of medium components onto particle surfaces. The effective diameter of microspheres prepared in fed intestinal lipids significantly increased compared to maleate buffer, but it was noted that the measured differences in particle size alone are not likely to result in the measured differences in diffusivities. The measured particle sizes are on the same order as the reported mesh size of mucus $(\sim 100 \mathrm{~nm}[35,43])$, potentially resulting in a greater reduction in diffusivity due to increased size. However, the likely association of exogenous lipids with mucus components, taken together with reported changes in mucus rheological properties with removal of endogenous lipids [9, 11], and observed structural changes in the presence of lipids, support changes in mucus structure and/or interactions with diffusing entities upon exposure to exogenous lipids. It is possible that exogenous lipids associate with hydrophobic portions of mucin molecules and effectively bridge mucin molecules and/or increase effective mucin network hydrophobic surface area. It is also noted that the measured particle sizes in test media reflect contributions from colloidal structures present in test media, including emulsion droplets in fed state medium and micelles in fed state medium and model bile.

Changes in mucus barrier properties upon exposure to medium with elevated $\left[\mathrm{Ca}^{2+}\right]$ or low $\mathrm{pH}$ may be due to altered electrostatic interactions. Most mucus glycoproteins contain significant levels of sialic acid and sulfated oligosaccharides, which results in a highly negatively charged mucus surface [44]. In addition to charged electrostatic interactions, mucin fibers likely interact via hydrophobic or hydrogen bond interactions [45]. The observed correlation between surface charge in maleate buffer and particle transport is consistent with the molecular interactions expected between diffusing microspheres and the network structure of mucin fibers. Electrostatic repulsive forces between negatively charged mucin fibers and negatively charged carboxylate and sulfate-modified microspheres potentially shift particle transport to regions where lowviscosity pores of the mucus mesh are present [46], resulting in less hindered particle transport. In contrast, the adhesivity of cationic amine-modified microspheres to anionic mucus glycoproteins severely retarded particle transport. Increased calcium ion concentration may reduce anionic functionalities through electrostatic interactions, while acidity likely reduces the negative charges of the carboxyl groups on sialic acid within the mucin fibers. Reductions in mucin-mucin electrostatic repulsion occurring upon exposure to elevated $\left[\mathrm{Ca}^{2+}\right]$ or decreased $\mathrm{pH}$ may act to enhance cross-linking within mucus. Reduced particle-mucin electrostatic repulsion may also contribute to lower particle diffusivities.

Increased calcium ion concentration again resulted in moderate $(\sim 20 \mathrm{~nm})$ changes in particle diameter that were unlikely to result in the observed changes in diffusivity within mucus. In addition, both increased calcium ion concentration and acidity altered particle surface potential, making it more positive in the case of amine-modified microspheres and more 
neutral in the case of sulfate- and carboxylate-modified microspheres. These changes in particle surface charge could result in enhanced interactions with anionic functionalities and hydrophobic regions, respectively, of mucin molecules. It is difficult to experimentally separate particle size and surface charge effects from changes in mucus structure. Regardless, the phenomena observed upon exposing mucus to exogenous media likely mimic those experienced in vivo at the mucosal surface.

In considering the impact of food-associated stimuli on particulate oral delivery systems, it may be advantageous to design delivery systems that are not impacted by these stimuli, especially if particles are intended for cellular uptake at the epithelial surface. As described above, both changes in effective mucus pore size and changes in intermolecular interactions may contribute to changes in mucus barrier properties upon exposure to food-associated stimuli. Thus, multiple approaches including control of particle size and surface chemistry might be explored for designing particles not impacted by food-associated mucosal barrier changes. For example, it has been demonstrated that polyethylene glycol coatings enhance particle transport through mucus, likely by minimizing intermolecular interactions [47].

Multiple animal models were used as sources of intestinal mucus in these studies due to practical experimental considerations. For example, porcine intestine provides large amounts of mucus for in vitro particle tracking experiments, but a rodent model was available to use for in vivo studies. It is noted that similar trends in mucus response to food-associated stimuli were observed across the different species.

In summary, stimuli generally associated with the universal activity of eating: presence of food-associated lipids, decrease in $\mathrm{pH}$, and increase in $\left[\mathrm{Ca}^{2+}\right]$, all enhance mucus barrier properties. These effects may have marked physiological significance. Many orally delivered drug compounds experience higher oral bioavailability in the fed state [48]. Perhaps this is related to particulate matter associated with food being retained in the upper intestine, the region of the intestine where the bulk of oral absorption generally occurs [49], through entrapment within mucus. In addition, enhanced barrier properties of intestinal mucus may help protect against exposure to microorganisms in food and/or mechanical irritation from food particulate matter eating, on intestinal mucus barrier properties. The results suggest that relatively mild stimuli can be utilized to modulate mucus barrier properties, an effect that can perhaps be exploited in enabling efficient drug delivery and/or preventing intestinal infection.

\section{CONCLUSION}

The intestinal mucus barrier significantly modulates pathogen invasion and oral drug delivery. The potential impact of the ubiquitous process of eating on intestinal mucus barrier properties was explored for the first time. Results indicate a significant impact of foodassociated lipids and other stimuli associated with eating ( $\mathrm{pH}$ modification, elevated $\left[\mathrm{Ca}^{2+}\right]$ ) on particulate diffusion through intestinal mucus, ability of particles to reach underlying epithelium, and mucus structure. These results have important implications for effective design of oral therapies (e.g., vaccines) and support exploration of mild stimuli for modulating intestinal mucus to facilitate drug delivery or hinder infection. 


\section{Supplementary Material}

Refer to Web version on PubMed Central for supplementary material.

\section{ACKNOWLEDGMENTS}

We thank Dr. Sean Sullivan for his valuable contributions to animal protocol design. The authors thank Dr. Selena DiMaio with her help in formulating the modeled fed state intestinal contents and Dr. Lay-Hong Ang for histology experiments. We gratefully acknowledge financial support from Merck, Inc. and National Institutes of Health Grant R21EB015750.

\section{REFERENCES}

1. Celli JP, Turner BS, Afdhal NH, Ewoldt RH, McKinley GH, Bansil R, Erramilli S. Rheology of gastric mucin exhibits a pH-dependent sol-gel transition. Biomacromolecules. 2007; 8:1580-1586. [PubMed: 17402780]

2. Lai SK, Wang YY, Wirtz D, Hanes J. Micro- and macrorheology of mucus. Adv Drug Deliv Rev. 2009; 61:86-100. [PubMed: 19166889]

3. Lai SK, Wang YY, Hanes J. Mucus-penetrating nanoparticles for drug and gene delivery to mucosal tissues. Adv Drug Deliv Rev. 2009; 61:158-171. [PubMed: 19133304]

4. Atuma C, Strugala V, Allen A, Holm L. The adherent gastrointestinal mucus gel layer: thickness and physical state in vivo. Am J Physiol Gastrointest Liver Physiol. 2001; 280:922-929.

5. Golding M, Wooster T. The influence of emulsion structure and stability on lipid digestion. Curr Opin Colloid Interface Sci. 2010; 15:90-101.

6. Porter CJ, Trevaskis NL, Charman WN. Lipids and lipid-based formulations: optimizing the oral delivery of lipophilic drugs. Nat Rev Drug Discov. 2007; 6:231-248. [PubMed: 17330072]

7. Larhed AW, Artursson P, Björk E. The Influence of Intestinal Mucus Components on the Diffusion of Drugs. Pharm Res. 1998; 15:66-71. [PubMed: 9487548]

8. Cone, RA. Mucus.. In: Ogra, PL.; Lamm, ME.; Strober, W.; McGhee, JR.; Mestecky, J.; Bienenstock, J., editors. Mucosal Immunology. 3 Ed. Academic; San Diego: 1999. p. 43-64.

9. Girod S, Zahm JM, Plotkowski C, Beck G, Puchelle E. Role of the physiochemical properties of mucus in the protection of the respiratory epithelium. Eur Respir J. 1992; 5:477-487. [PubMed: 1563506]

10. Widdicombe JG. Role of lipids in airway function. Eur J Respir Dis Suppl. 1987; 153:197-204. [PubMed: 3322862]

11. Murty VL, Sarosiek J, Slomiany A, Slomiany BL. Effect of lipids and proteins on the viscosity of gastric mucus glycoprotein. Biochem Biophys Res Commun. 1984; 121:521-529. [PubMed: 6732822]

12. Galabert C, Jacquot J, Zahm JM, Puchelle E. Relationships between the lipid content and the rheological properties of airway secretions in cystic fibrosis. Clin Chim Acta. 1987; 164:139-149. [PubMed: 3594907]

13. Girod S, Galabert C, Lecuire A, Zahm JM, Puchelle E. Phospholipid composition and surfaceactive properties of tracheobronchial secretions from patients with cystic fibrosis and chronic obstructive pulmonary diseases. Pediatr Pulmonol. 1992; 13:22-27. [PubMed: 1589308]

14. Zahm JM, Galabert C, Chaffin A, Chazalette JP, Grosskopf C, Puchelle E. Improvement of cystic fibrosis airway mucus transportability by recombinant human DNase is related to changes in phospholipid profile. Am J Respir Crit Care Med. 1998; 157:1779-1784. [PubMed: 9620905]

15. Crowther RS, Marriott C, James SL. Cation induced changes in the rheological properties of purified mucus glycoprotein gels. Biorheology. 1984; 21:253-263. [PubMed: 6466792]

16. Steiner CA, Litt M, Nossal R. Effect of Ca++ on the structure and rheology of canine tracheal mucin. Biorheology. 1984; 21:235-252. [PubMed: 6466791]

17. Raynal BD, Hardingham TE, Sheehan JK, Thornton DJ. Calcium-dependent protein interactions in MUC5B provide reversible cross-links in salivary mucus. J Biol Chem. 2003; 278:28703-28710. [PubMed: 12756239] 
18. Herrmann A, Davies JR, Lindell G, Mårtensson S, Packer NH, Swallow DM, Carlstedt I. Studies on the "insoluble" glycoprotein complex from human colon. Identification of reduction-insensitive MUC2 oligomers and C-terminal cleavage. J Biol Chem. 1999; 274:15828-15836. [PubMed: 10336486]

19. Di Maio S, Carrier RL. Gastrointestinal contents in fasted state and post-lipid ingestion: In vivo measurements and in vitro models for studying oral drug delivery. J Control Release. 2011; 151:110-122. [PubMed: 21134406]

20. Gura, KM.; Chan, LN. Drug therapy and role of nutrition. In: Duggan, CW.; Walker, JB.; W. A., editors. Nutrition in pediatrics: basic science and clinical applications. BC Decker Inc; Hamilton: 2008. p. 191-208.

21. Dressman JB, Berardi RR, Dermentzoglou LC, Russell TL, Schmaltz SP, Barnett JL, Jarvenpaa KM. Upper gastrointestinal (GI) pH in young, healthy men and women. Pharm Res. 1990; 7:756761. [PubMed: 2395805]

22. Bhaskar KR, Gong DH, Bansil R, Pajevic S, Hamilton JA, Turner BS, LaMont JT. Profound increase in viscosity and aggregation of pig gastric mucin at low $\mathrm{pH}$. Am J Physiol. 1991; 261:827-832.

23. Lieleg O, Vladescu I, Ribbeck K. Characterization of particle translocation through mucin hydrogels. Biophys J. 2010; 98:1782-1789. [PubMed: 20441741]

24. Cao X, Bansil R, Bhaskar KR, Turner BS, LaMont JT, Niu N, Afdhal NH. pH-dependent conformational change of gastric mucin leads to sol-gel transition. Biophys J. 1999; 76:12501258. [PubMed: 10049309]

25. Hong Z, Chasan B, Bansil R, Turner BS, Bhaskar KR, Afdhal NH. Atomic Force Microscopy Reveals Aggregation of Gastric Mucin at Low pH. Biomacromolecules. 2005; 6:3458-3466. [PubMed: 16283779]

26. Suh J, Wirtz D, Hanes J. Real-time intracellular transport of gene nanocarries studied by multiple particle tracking. Biotechnol Prog. 2004; 20:598-602. [PubMed: 15059007]

27. Suh J, Dawson M, Hanes J. Real-time multiple-particle tracking: Applications to drug and gene delivery. Adv Drug Deliv Rev. 2005; 57:63-78. [PubMed: 15518921]

28. Thornton DJ, Sheehan JK. From mucins to mucus: toward a more coherent understanding of this essential barrier. Proc Am Thorac Soc. 2004; 1:54-61. [PubMed: 16113413]

29. Buyukozturk F, Di Maio S, Budil DE, Carrier RL. Effect of Ingested Lipids on Drug Dissolution and Release with Concurrent Digestion: A Modeling Approach. Pharm Res. 2013; 30:3131-3144. [PubMed: 24234918]

30. Crater JS, Carrier RL. Barrier Properties of Gastrointestinal Mucus to Nanoparticle Transport. Macromol Biosci. 2010; 10:1473-1483. [PubMed: 20857389]

31. Sbalzarini IF, Koumoutsakos P. Feature point tracking and trajectory analysis for video imaging in cell biology. J Struct Biol. 2005; 151:182-195. [PubMed: 16043363]

32. Tang BC, Dawson M, Lai SK, Wang YY, Suk JS, Yang M, Zeitlin P, Boyle MP, Fu J, Hanes J. Biodegradable polymer nanoparticles that rapidly penetrate the human mucus barrier. Proc Natl Acad Sci USA. 2009; 106:19268-19273. [PubMed: 19901335]

33. Matsuo K, Ota H, Akamatsu T, Sugiyama A, Katsuyama T. Histochemistry of the surface mucous gel layer of the human colon. Gut. 1997; 40:782-789. [PubMed: 9245933]

34. Ota H, Katsuyama T. Alternating laminated array of two types of mucin in the human gastric surface mucous layer. Histochem J. 1992; 24:86-92. [PubMed: 1374372]

35. Van der Waaij LA, Harmsen HJ, Madjipour M, Kroese FG, Zwiers M, van Dullemen HM, de Boer NK, Welling GW, Jansen PL. Bacterial population analysis of human colon and terminal ileum biopsies with 16S rRNA-based fluorescent probes: Commensal bacteria live in suspension and have no direct contact with epithelial cells. Inflamm Bowel Dis. 2005; 11:865-871. [PubMed: 16189415]

36. Jordan N, Newton J, Pearson J, Allen A. A novel method for the visualization of the in situ mucus layer in rat and man. Clin Sci. 1998; 95:97-106. [PubMed: 9662491]

37. Lehr CM, Poelma FGJ, Junginger HE, Tukker JJ. An estimate of turnover time of intestinal mucus gel layer in the rat in situ loop. Int J Pharm. 1991; 70:235-240. 
38. Lentz KA. Current methods for predicting human food effect. AAPS J. 2008; 10:282-288. [PubMed: 18500565]. [PubMed: 18500565]

39. Singh BN. A quantitative approach to probe the dependence and correlation of food-effect with aqueous solubility, dose/solubility ratio, and partition coefficient $(\log \mathrm{P})$ for orally active drugs administered as immediate-release formulations. Drug Develop Res. 2005; 65:55-75.

40. Kim KC, Singh BN. Association of lipids with mucins may take place prior to secretion: studies with primary hamster tracheal epithelial cells in culture. Biorheology. 1990; 27:491-501. [PubMed: 2261515]

41. Kim KC, Singh BN. Hydrophobicity of mucin-like glycoproteins secreted by cultured tracheal epithelial cells: association with lipids. Exp Lung Res. 1990; 16:279-292. [PubMed: 2357950]

42. Larhed AW, Artursson P, Björk E. The influence of intestinal mucus components on the diffusion of drugs. Pharm Res. 2005; 15:66-71. [PubMed: 9487548]

43. Pullan RD, Thomas GA, Rhodes M, Newcombe RG, Williams GT, Allen A, Rhodes J. Thickness of adherent mucus gel on colonic mucosa in humans and its relevance to colitis. Gut. 1994; 35:353-359. [PubMed: 8150346]

44. Shogren R, Gerken TA, Jentoft N. Role of glycosylation on the conformation and chain dimensions of O-linked glycoproteins: light-scattering studies of ovine submaxillary mucin. Biochemistry. 1989; 28:5525-5536. [PubMed: 2775721]

45. Wang YY, Lai SK, Suk JS, Pace A, Cone R. Addressing the PEG muco-adhesivity paradox to engineer nanoparticles that "slip" through the human mucus barrier. Angew Chem Int Ed Engl. 2008; 47:9726-9729. [PubMed: 18979480]

46. Dawson M, Krauland E, Wirtz D, Hanes J. Transport of polymeric nanoparticle gene carriers in gastric mucus. Biotechnol Prog. 2004; 20:851-857. [PubMed: 15176891]

47. Lai SK, O'Hanlon DE, Harrold S, Man ST, Wang YY, Cone R, Hanes J. Rapid transport of large polymeric nanoparticles in fresh undiluted human mucus. Proc Natl Acad Sci USA. 2007; 104:1482-1487. [PubMed: 17244708]

48. Chow HH, Hakim IA, Vining DR, Crowell JA, Ranger-Moore J, Chew WM, Celaya CA, Rodney SR, Hara Y, Alberts DS. Effects of dosing condition on the oral bioavailability of green tea catechins after single-dose administration of Polyphenon E in healthy individuals. Clin Cancer Res. 2005; 11:4627-4633. [PubMed: 15958649]

49. Pang KS. Modeling of intestinal drug absorption: roles of transporters and metabolic enzymes. Drug Metab and Dispos. 2003; 31:1507-1519. 

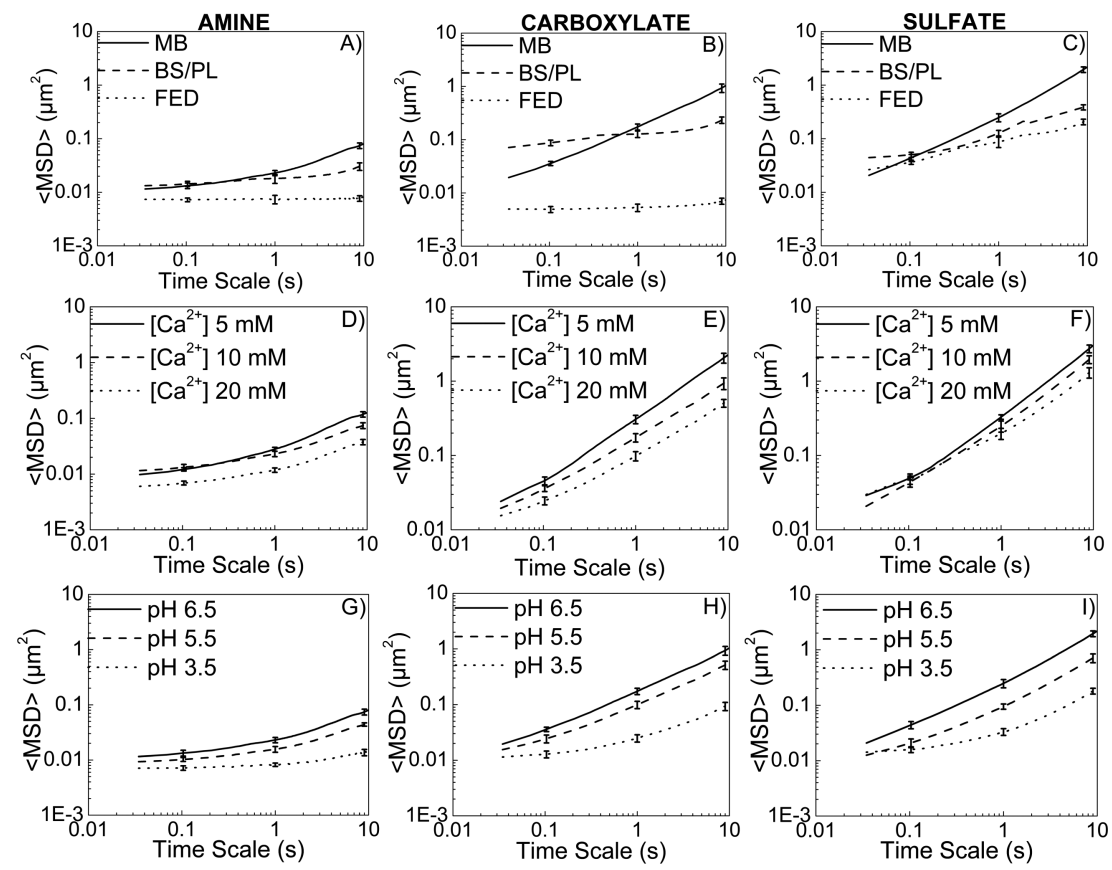

Figure 1.

(A-C) Bile components and food-associated lipids hinder particulate transport in intestinal mucus. Ensemble $<\mathrm{MSD}>$ versus time scale plots for A) amine- B) carboxylate-, C) sulfatemodified microspheres in porcine intestinal mucus. $\mathrm{MB}=$ maleate buffer, $\mathrm{BS} / \mathrm{PL}=$ bile salt/ phospholipid mixture, FED = model fed state intestinal contents. (D-F) Increasing $\left[\mathrm{Ca}^{2+}\right]$ hinders particulate transport in intestinal mucus. Ensemble $<\mathrm{MSD}>$ versus time scale plots for D) amine- E) carboxylate-, F) sulfate-modified microspheres in porcine intestinal mucus. (G-H) Decreasing pH hinders particulate transport in intestinal mucus. Ensemble $\langle$ MSD $>$ versus time scale plots for $\mathrm{G}$ ) amine- H) carboxylate-, I) sulfate-modified microspheres in porcine intestinal mucus. 

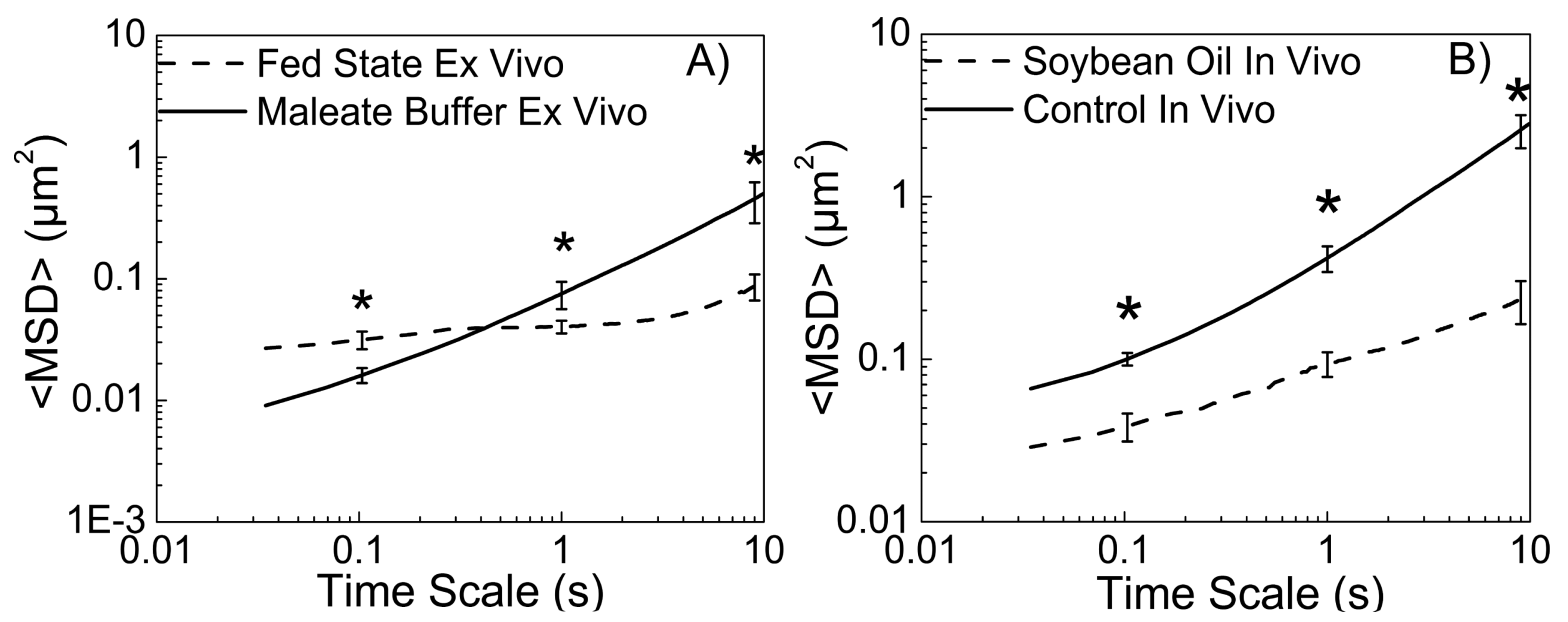

Figure 2.

Ensemble $<$ MSD $>$ versus time scale plots for carboxylate-modified microspheres in A) mouse intestinal explants, B) rat intestinal explants after in vivo oral soybean oil dosing. 


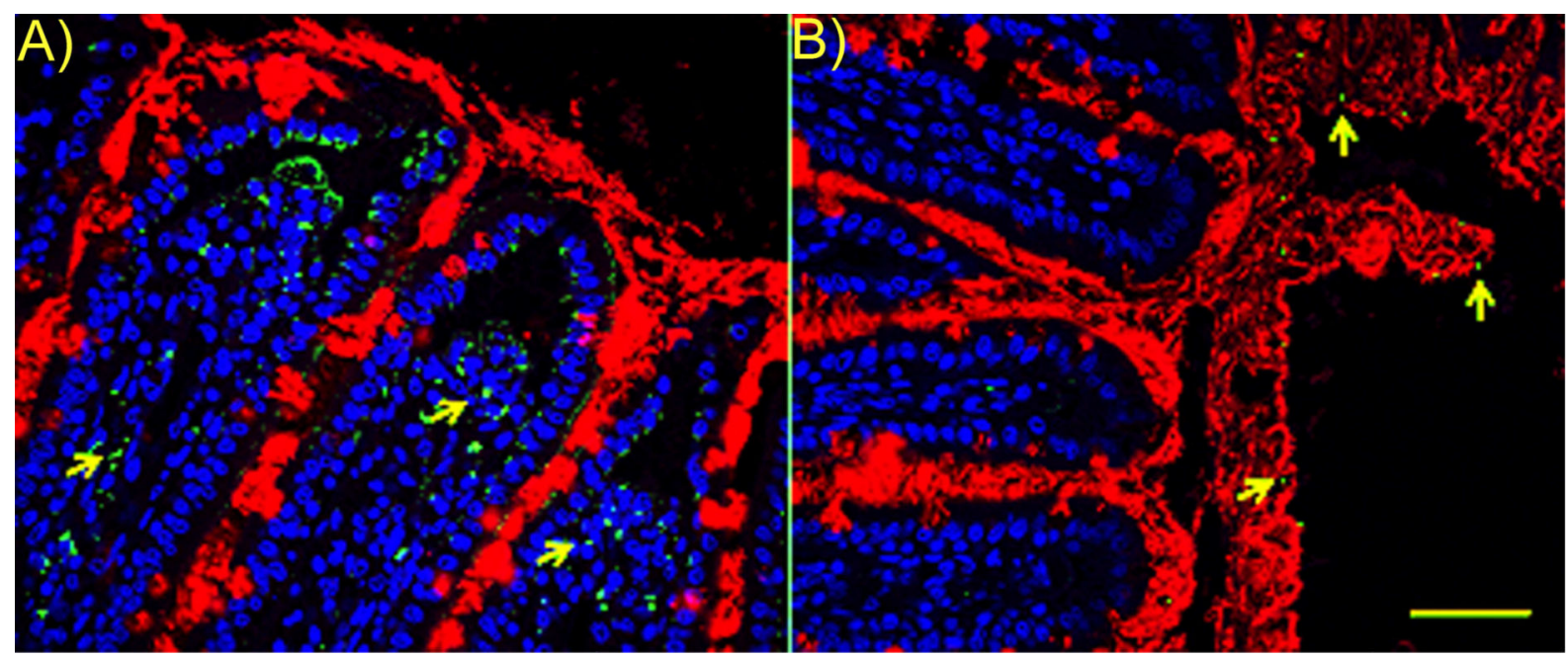

Figure 3 .

Lectin (red) - Hoescht (blue) staining of rat small intestine demonstrating distribution of green-fluorescent microspheres (arrows) in A) control and B) rats orally dosed soybean oil 1 hr before dosing microspheres. Bar $=20 \mu \mathrm{m}$. 


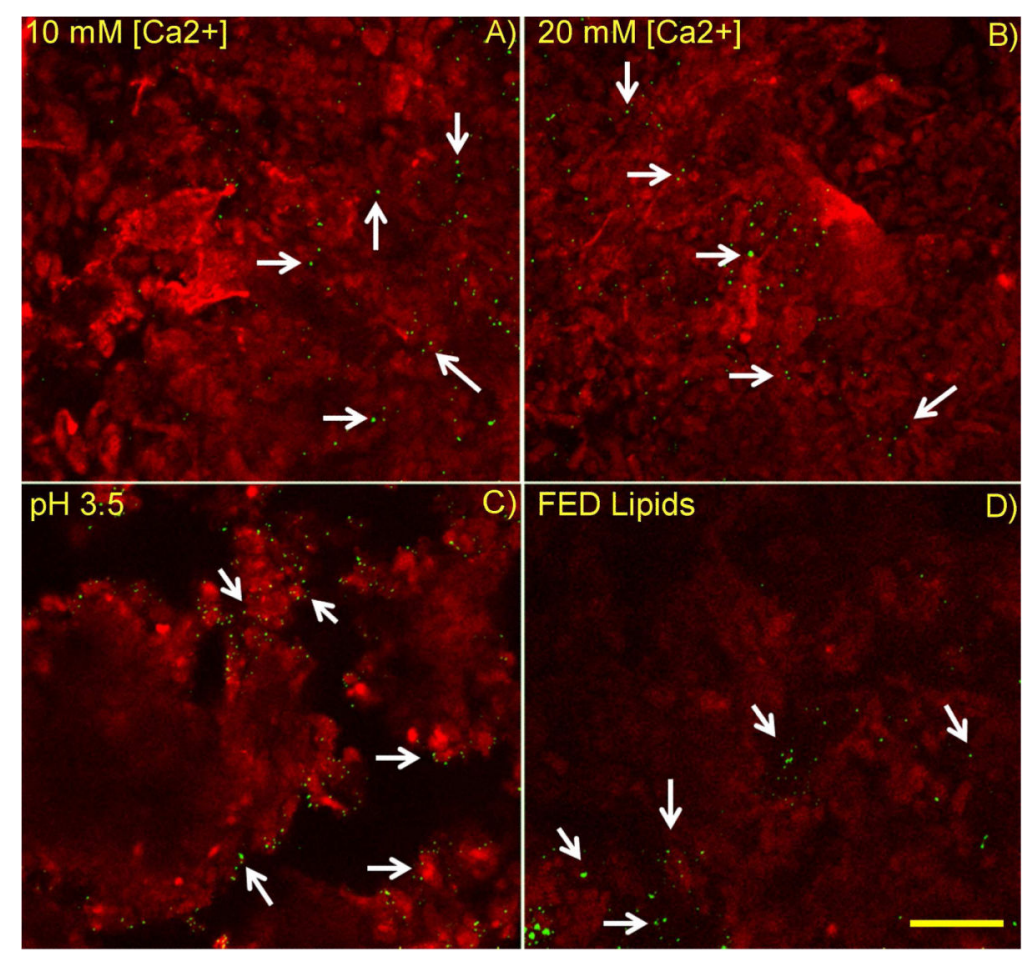

Figure 4.

Lipids and $\mathrm{pH}$ changes alter mucus structure and microparticle distribution within mucus. Microspheres dosed to mucus were diluted in A) Maleate buffer at $\mathrm{pH} 6.5$ and $\left[\mathrm{Ca}^{2+}\right]=10$ $\mathrm{mM} \mathrm{B})$ Maleate buffer at $\left[\mathrm{Ca}^{2+}\right]=20 \mathrm{mM}, \mathrm{C}$ ) Maleate buffer at $\mathrm{pH} 3.5$, D) Fed state lipids, including model bile components phospholipid and bile salt. Mucus appears more uniform and microspheres were dispersed more homogeneously for cases A and B. Bar $=50 \mu \mathrm{m}$. 


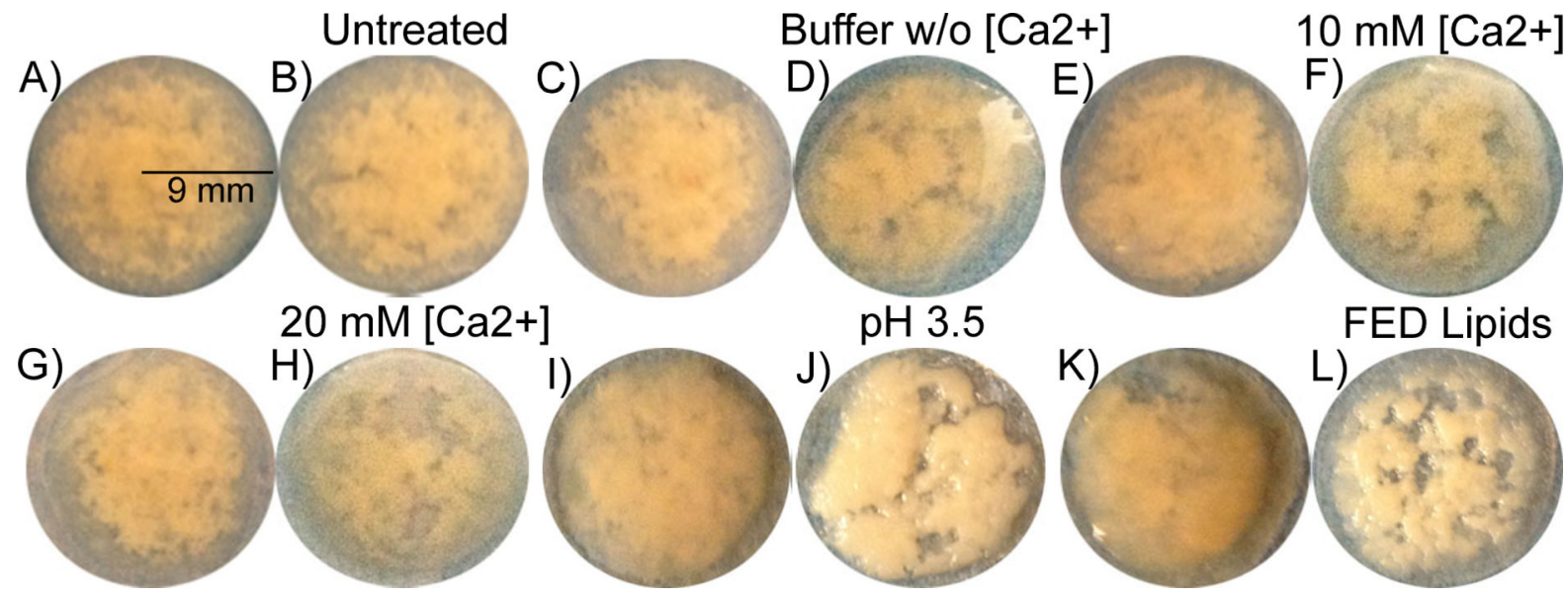

Figure 5.

Macroscopic changes in mucus structure are visible after exposure to $\mathrm{Ca}^{2+}$, low $\mathrm{pH}$ medium or food-associated lipids and bile components. Mucus samples are shown before (A, C, E, G, I, K) and after $2 \mathrm{hr}$ exposure (B, D, F, H, J, L) to various media. 


\section{Table 1}

Bio-relevant media dosed to mucosal surfaces.

\begin{tabular}{lllcc}
\cline { 2 - 4 } & & Triz-Ma & 100 & $\mathrm{mM}$ \\
& $\mathrm{NaCl}$ & 65 & $\mathrm{mM}$ \\
& Maleate Buffer & $\mathrm{CaCl}_{2}$ & $5-20$ & $\mathrm{mM}$ \\
& $\mathrm{NaN}_{3}$ & 3 & $\mathrm{mM}$ \\
& $\mathrm{NaOH}$ & $0-40$ & $\mathrm{mM}$ \\
\cline { 2 - 5 } & Model Bile & NaTDC & 12 & $\mathrm{mM}$ \\
& Lecithin & 4 & $\mathrm{mM}$ \\
\cline { 2 - 5 } & & Soybean Oil & 35 & $\mathrm{mM}$ \\
& Lipid & Sodium Oleate & 30 & $\mathrm{mM}$ \\
& 1 -Oleoyl-rac-glycerol & 15 & $\mathrm{mM}$ \\
\hline
\end{tabular}

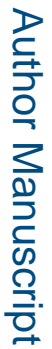

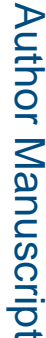

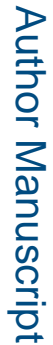

